\title{
Potential for treatment benefit of small molecule CGRP receptor antagonist plus monoclonal antibody in migraine therapy
}

Kathleen Mullin, MD, David Kudrow, MD, Robert Croop, MD, Meghan Lovegren, BS, Charles M. Conway, PhD, Vladimir Coric, MD, and Richard B. Lipton, MD

Neurology ${ }^{\circledR}$ 2020;94:e2121-e2125. doi:10.1212/WNL.0000000000008944

\section{Abstract}

\section{Objective}

To provide the first clinical report that 2 calcitonin gene-related peptide (CGRP) therapies, a small molecule CGRP receptor antagonist and an anti-CGRP receptor antibody, can be used concomitantly to treat refractory migraine.

\section{Methods}

Case reports are presented of 2 patients participating in a long-term safety study of rimegepant $75 \mathrm{mg}$ oral tablets for acute treatment (NCT03266588). After Food and Drug Administration approval of erenumab, both patients started subcutaneous erenumab monthly as allowed per protocol.

\section{Results}

Patients were women 44 and 36 years of age with $\geq 2$ decades of self-reported suboptimal response to multiple migraine medications. Patient 1 used rimegepant for 6 months and then started erenumab $70 \mathrm{mg}$ subcutaneous monthly. Despite a response to preventive treatment with erenumab, she experienced substantial relief treating 7 of 7 acute attacks with rimegepant and eliminated regular, frequent use of ibuprofen and a caffeinated analgesic. Patient 2 used rimegepant for 60 days before starting erenumab $140 \mathrm{mg}$ subcutaneously monthly. While on erenumab, 9 of 9 attacks treated with rimegepant responded. She stopped near-daily use of injectable ketorolac and diphenhydramine. While using rimegepant alone or together with erenumab, patients reported no related adverse events.

\section{Conclusions}

Rimegepant $75 \mathrm{mg}$ may be effective for acute treatment during concomitant erenumab preventive administration. The mechanism underlying the benefits of concomitant use of a small molecule CGRP receptor antagonist and an anti-CGRP receptor antibody is unknown and requires further study.

\section{ClinicalTrials.gov identifier \\ NCT03266588.}

\section{Classification of evidence}

This study provides Class IV evidence that for patients with migraine using erenumab, rimegepant is effective for acute treatment.

\author{
Correspondence \\ Dr. Mullin \\ kate@neinh.com
}

\section{MORE ONLINE}

$\rightarrow$ Class of Evidence

Criteria for rating

therapeutic and diagnostic

studies

NPub.org/coe 


\section{Glossary}

cAMP = cyclic adenosine monophosphate; CGRP = calcitonin gene-related peptide; $\mathbf{m A b}=$ monoclonal antibody; $\mathbf{M M D}=$ monthly migraine day; ONS = occipital nerve stimulator.

Calcitonin gene-related peptide (CGRP) plays a crucial role in migraine pathophysiology and is now established as an important target for both preventive and acute treatments. ${ }^{1,2}$ The current approved preventive CGRP-targeting treatments are monoclonal antibodies (mAbs) that bind either the CGRP receptor or the CGRP ligand. Small molecule CGRP receptor antagonists, known as gepants, are in development for acute and preventive treatment. In anticipation of approval of the gepants, questions have arisen about their combined use in patients on mAbs. If the CGRP signaling pathway is already blocked, will gepants be effective on top of mAbs? We recently observed 2 patients enrolled in a long-term safety study of rimegepant who started treatment with erenumab, a CGRP receptor-targeted $\mathrm{mAb}$. These 2 patients provide preliminary observations that gepants may be effective for migraine attacks occurring during preventive CGRP $m A b$ therapy and that $m A b s$ remain effective for migraine prevention during the coadministration of gepants for acute treatment.

\section{Methods}

This article summarizes the cases of 2 patients with migraine who were participating in a long-term safety study of rimegepant $75 \mathrm{mg}$ oral tablets for acute treatment (ClinicalTrials. gov identifier: NCT03266588). While use of investigational biological agents was prohibited by the protocol, after erenumab approval by the US Food and Drug Administration (May 2018), both patients started subcutaneous monthly preventive therapy. The long-term safety study protocol was approved by independent institutional review boards and/or ethics committees at each trial center. No statistical analyses were performed on the results reported herein; they are based on patient report and investigator observation.

\section{Patient 1}

The first patient is a 44 year-old white woman with a history of migraine without aura since 1995. Before enrollment in a trial of rimegepant, she reported an average of 8 attacks with pain of moderate to severe intensity per month during the preceding 3 months. She treated acutely with sumatriptan $100 \mathrm{mg}$ oral tablets or a fixed combination of acetaminophen, acetylsalicylic acid, and caffeine. Ibuprofen was used as needed for dysmenorrhea and migraine.

During a 30-day lead-in phase of the clinical trial, the patient used sumatriptan to treat 10 migraine attacks of moderate to severe pain intensity. After the lead-in phase, she entered the treatment phase of the long-term safety trial and received rimegepant $75 \mathrm{mg}$ as needed, up to once daily, for the acute treatment of migraine. Within 1 week, she discontinued ibuprofen for migraine, and she stopped the caffeinecontaining analgesic 5 weeks after entering into treatment with rimegepant $75 \mathrm{mg}$.

Although her acute attacks responded well to treatment with rimegepant $75 \mathrm{mg}$, attacks were frequent, and after 6 months in the rimegepant long-term safety study, she was started on erenumab $70 \mathrm{mg}$ subcutaneous monthly as a preventive therapy. After starting erenumab, her monthly migraine days (MMDs) declined by $46 \%$ over the first 4 weeks from 13 to 7 MMDs of any pain intensity, but she continued to experience migraine attacks. Over the subsequent month, she treated 7 breakthrough migraine attacks that occurred while on erenumab with rimegepant $75 \mathrm{mg}$ oral tablet. Attacks were relieved each time. No other acute migraine medications were needed to resolve the rimegepant-treated attacks. While receiving rimegepant alone, she experienced 1 adverse event of streptococcal pharyngitis that was considered by the investigator to be unrelated to rimegepant. While receiving rimegepant alone or concomitantly with erenumab, she experienced no adverse events related to treatment. At the end-of-study visit, she reported that she was very satisfied with rimegepant and rated it "much better" than previous treatments.

\section{Patient 2}

The second patient is a 36 year-old white woman with a 19year history of migraine without aura. She reported an average of 11 MMDs with pain of moderate to severe intensity. Her treatment history involved subcutaneous sumatriptan, intranasal zolmitriptan, and oral tablets of rizatriptan, eletriptan, naratriptan, and almotriptan, all of which were suboptimal (e.g., relief took too long, did not last, was inconsistent). She also had a 6-year history of treatment with an implanted occipital nerve stimulator (ONS). At enrollment, her migraine treatments included oral sumatriptan $100 \mathrm{mg}$, IM ketorolac tromethamine $30 \mathrm{mg}$, IM diphenhydramine $100 \mathrm{mg}$, oral methadone $80 \mathrm{mg}$, oral ondansetron $8 \mathrm{mg}$, oral zonisamide $250 \mathrm{mg}$, and ONS. Before enrollment, she stopped using methadone, a prohibited medication for the trial.

During a 30-day run-in to the long-term safety trial, the patient experienced 22 attacks of moderate to severe pain intensity. On entry into the treatment phase, she received 30 tablets of rimegepant $75 \mathrm{mg}$ and was instructed to take rimegepant $75 \mathrm{mg}$ up to once per calendar day, as needed, for the acute treatment of migraine attacks of any pain intensity. In the first 30 days of treatment, she used 16 doses of rimegepant; in the second 30 days, she used 11 doses of 
rimegepant and stopped ondansetron, ketorolac, and diphenhydramine. Because of high headache frequency, she was subsequently started on a monthly dose of erenumab $140 \mathrm{mg}$. Over the first 30 days after starting erenumab, she experienced 9 attacks, all of which were treated successfully with rimegepant. While using rimegepant alone or together with erenumab, she experienced no adverse events.

\section{Discussion}

Rimegepant $75 \mathrm{mg}$ oral tablet and erenumab $70 \mathrm{mg}$ and $140 \mathrm{mg}$ subcutaneous injection have demonstrated efficacy in separate randomized controlled clinical trials for acute and preventive treatment of migraine, respectively. ${ }^{3-5}$ The response to erenumab in these patients appears typical. However, with histories of long-term polypharmacy with acute medications, both patients were at risk of failing preventive treatment. While the initiation of erenumab reduced MMDs, the onset of treatment with rimegepant enabled the first patient to end 22 years of acute treatment with a caffeinecontaining combination analgesic. The second patient eliminated near-daily use of 2 injectable medications: an IM nonsteroidal anti-inflammatory drug and an IM antinauseant. In the long term, the reduction of attack frequency and the elimination of regular, frequent use of multiple acute medications are likely to be of substantial clinical import to these patients.

The profile of benefit seen in clinical trials and experiences with rimegepant and erenumab tend to be similar to those described herein and suggest that both compounds will have a meaningful role in the migraine armamentarium. The benefits of their concomitant use may involve additive effects and may be generalizable to other combinations of antiCGRP agents with distinct molecular targets. Because it is a small case series, this study provides Class IV evidence that combining rimegepant with erenumab may provide effective and safe treatment of patients with a history of refractory migraine.

Because both of these antimigraine agents target the CGRP receptor, it is unknown what mechanism(s) underlie the acute and preventive treatment benefits seen during concomitant treatment. It is unlikely that differences in affinity are a factor, because both molecules exhibit similar high (20-30 pmol/L) affinity for the human CGRP receptor. ${ }^{6,7}$ In contrast, given the disparate physical size of these 2 agents, it is conceivable that the therapeutic benefits of coadministration may involve functional antagonism of a pool of CGRP receptors that are more readily available to the $280 \times$ smaller rimegepant $(0.53 \mathrm{kDa})$ than to the biologic antagonist erenumab $(\approx 150 \mathrm{kDa})$. For example, membranebound CGRP receptors are known to internalize into endosomes after CGRP agonist stimulation. ${ }^{8,9}$ Mechanistic studies in cellular and animal behavior assays have shown that these internalized CGRP receptors can continue to actively drive CGRP-mediated pain signals. ${ }^{10}$ Given that the truncated peptide antagonist CGRP (8-37), conjugated to cholesterol for endosome-specific targeting, can suppress CGRP-mediated endosomal signaling and inhibit both cellular signals and animal pain responses, ${ }^{10}$ it is possible that a differential ability for small molecules vs mAbs to enter cells and engage endosomal CGRP receptors may be a factor. The lipophilicity $(\log \mathrm{D} 2.08)$ and inherent membrane permeability of rimegepant ${ }^{6}$ would provide for potential ready access to endosome-bound CGRP receptors, regardless of whether the neuropeptide CGRP is present or absent. In contrast, neither receptor-targeted nor ligand-targeted CGRP mAbs are localized with internalized CGRP receptors in the presence of CGRP. ${ }^{9}$ This may present a situation during migraine attacks (when CGRP levels are most elevated $^{11}$ ) in which the 2 agents have differential access to an endosome-bound CGRP-mediated pain signaling pathway and rimegepant might provide additional benefits to ongoing $\mathrm{mAb}$ therapy.

Additional evidence of differential intracellular action comes from functional antagonism studies of CGRP-mediated signaling via cyclic adenosine monophosphate (cAMP). Despite their comparable binding affinity for the human CGRP receptor, erenumab is $16 \times$ less potent than rimegepant at antagonism of cAMP signaling in whole-cell assays. ${ }^{6,7}$ Consequently, an additive benefit of combination therapy may derive from enhanced inhibition of CGRP-mediated intracellular cAMP signaling cascades.

Alternatively, the observed therapeutic actions may be related to differential receptor kinetics of CGRP small molecules and CGRP mAbs. Rimegepant has demonstrated the ability to maintain CGRP receptor antagonism in vivo in primates even when repeatedly challenged by IV CGRP bolus delivery, ${ }^{6}$ whereas the ability of CGRP mAbs to withstand displacement by repeated waves of CGRP release is unknown. Differences in CGRP receptor turnover or CGRP receptor internalization in the presence of small molecule binding vs large antibody binding may also be involved. .,9 $^{8}$

Because rimegepant has $65 \times$ higher affinity for the human CGRP receptor vs the amylin-1 (CTR/RAMP1) receptor, the potential involvement of the amylin-1 receptor may seem less likely, because any engagement would be much less than for CGRP receptor inhibition. Nevertheless, this is a potential point of difference between the 2 molecules; erenumab is reported not to inhibit amylin- $1,^{7}$ although a definitive causal link between amylin-1 receptor inhibition and migraine has yet to emerge.

Additional studies will be needed to determine whether these or other differences are the primary drivers of the effectiveness of combination therapy with rimegepant and erenumab.

This is the first clinical report describing concomitant use of anti-CGRP therapies for acute and preventive treatment in 
patients with migraine. While CGRP antagonist antibodies have demonstrated efficacy in reducing attack frequency, most individuals who respond experience breakthrough attacks and continue to require acute treatment. Rimegepant $75 \mathrm{mg}$ oral tablet appears to offer utility as an acute treatment for migraine attacks that occur during preventive treatment with CGRP antagonist antibodies. The potential mechanisms underlying these benefits remain unknown. This question and others should be explored in future research.

Biohaven Pharmaceuticals will provide access to deidentified patient-level data that underlie the results in this article in response to scientifically valid research proposals. Data from this study, including the study protocol, will be made available beginning 9 months and ending 24 months after the publication of this article. Biohaven will consider requests from qualified researchers for access to the data. Proposals should be directed to the corresponding author. Biohaven will review the request using an internal committee composed of Biohaven colleagues who are responsible for the program, including a clinician, a statistician, and a data-sharing professional. Biohaven will make reasonable efforts to fulfill all data requests for legitimate research purposes, but there might be instances in which retrieval or delivery of data is not feasible such as those involving, for example, patient privacy, requirements for permissions, contractual obligations, and conflicts of interest. All those receiving access to data will be required to enter into a data use agreement provided by Biohaven, which will contain the terms under which the data will be provided.

\section{Author contributions}

K. Mullin and D.B. Kudrow: drafting/revising the manuscript, data acquisition, analysis or interpretation of data, accepts responsibility for conduct of research and will give final approval, study supervision, obtaining funding. R. Croop: drafting/revising the manuscript, data acquisition, study concept or design, analysis or interpretation of data, accepts responsibility for conduct of research and will give final approval, study supervision, obtaining funding. M. Lovegren: drafting/revising the manuscript, study concept or design, accepts responsibility for conduct of research and will give final approval, acquisition of data, study supervision. C.M. Conway: drafting/revising the manuscript, study concept or design, analysis or interpretation of data, accepts responsibility for conduct of research and will give final approval, study supervision. V. Coric: drafting/revising the manuscript, data acquisition, study concept or design, analysis or interpretation of data, accepts responsibility for conduct of research and will give final approval, acquisition of data, study supervision, obtaining funding. R.B. Lipton: drafting/revising the manuscript, study concept or design, analysis or interpretation of data, accepts responsibility for conduct of research and will give final approval.

\section{Acknowledgment}

Drs. Mullin and Lipton thank Daniel Sun, study coordinator for the Montefiore Headache Center. Dr. Kudrow thanks
Jaime Latorre, study coordinator at the California Medical Clinic for Headache. Drs. Croop, Conway, and Coric and Ms. Lovegren thank Jennifer Hould, senior clinical trial lead at Biohaven Pharmaceuticals, for data review. Medical writing services were provided by Christopher Caiazza, who, under the direction of the authors, assisted with revision of the original manuscript, added references, and ensured that the submission met journal guidelines.

\section{Study funding}

This study was funded and sponsored by Biohaven Pharmaceuticals, Inc.

\section{Disclosure}

K. Mullin serves as a consultant or advisory board member for or has received honoraria from Amgen, Biohaven, electroCore, and Eli Lilly. D. Kudrow has received fees for advisory board from Alder, Biohaven, Eli Lilly, Amgen, and Xoc and for speaker's bureau from Xoc, Teva, Amgen, Novartis, and Eli Lilly. He has also received research support from Amgen, Novartis, Eli Lilly, Teva, Alder, Biohaven, Biogen, and RocheGenentech. R. Croop, M. Lovegren, C. Conway, and V. Coric are employed by and hold stock/stock options in Biohaven Pharmaceuticals. R. Lipton serves on the Editorial Board of Neurology and Cephalalgia and as senior advisor to Headache but is not paid for his roles in Neurology or Headache. He has received research support from the NIH. He also receives support from the Migraine Research Foundation and the National Headache Foundation. He receives research grants from Allergan, Amgen, Dr. Reddy's Laboratories, and Novartis. He has reviewed for the National Institute on Aging and National Institute of Neurological Disorders and Stroke and serves as consultant or advisory board member for or has received honoraria from Alder, Allergan, Amgen, Autonomic Technologies, Avanir, Biohaven, Boston Scientific, CoLucid, Dr. Reddy's Laboratories, electroCore, Eli Lilly, eNeura Therapeutics, GlaxoSmithKline, Merck, Novartis, Teva, and Vedanta. He receives royalties from Wolff's Headache (8th edition, Oxford Press University, 2009) and Informa. He holds stock options in eNeura Therapeutics and Biohaven Pharmaceuticals. Go to Neurology.org/N for full disclosures.

\section{Publication history}

Received by Neurology April 15, 2019. Accepted in final form November 23, 2019.

\section{References}

1. Dubowchik GM, Bell IM. 7.05-CGRP receptor antagonists for the treatment of migraine. In: Chackalamannil S, Rotella D, Ward SE, editors. Comprehensive Medicinal Chemistry III. Oxford: Elsevier; 2017:176-224.

2. Edvinsson L, Haanes KA, Warfvinge K, Krause DN. CGRP as the target of new migraine therapies: successful translation from bench to clinic. Nat Rev Neurol 2018; 14:338-350.

3. Marcus R, Goadsby PJ, Dodick D, Stock D, Manos G, Fischer TZ. BMS-927711 for the acute treatment of migraine: a double-blind, randomized, placebo controlled, dose-ranging trial. Cephalalgia 2014;34:114-125.

4. Goadsby PJ, Reuter U, Hallström Y, et al. A controlled trial of erenumab for episodic migraine. N Engl J Med 2017;377:2123-2132.

5. Lipton RB, Croop R, Stock EG, et al. Rimegepant, an oral calcitonin gene-related peptide receptor antagonist, for migraine. N Engl J Med 2019;381:142-149.

6. Luo G, Chen L, Conway CM, et al. Discovery of (5S,6S,9R)-5-amino-6-(2,3difluorophenyl)-6,7,8,9-tetrahydro-5H-cyclohepta[b]pyri din-9-yl 4-(2-oxo-2,3- 
dihydro-1H-imidazo[4,5-b]pyridin-1-yl)piperidine-1-carboxylate (BMS-927711): an oral calcitonin gene-related peptide (CGRP) antagonist in clinical trials for treating migraine. J Med Chem 2012;55:10644-10651.

7. Shi L, Lehto SG, Zhu DX, et al. Pharmacologic characterization of AMG 334, a potent and selective human monoclonal antibody against the calcitonin gene-related peptide receptor. J Pharmacol Exp Ther 2016;356:223-231.

8. Gingell JJ, Hendrikse ER, Hay DL. New insights into the regulation of CGRP-family receptors. Trends Pharmacol Sci 2019;40:71-83.
9. Manoukian R, Sun H, Miller S, Shi D, Chan B, Xu C. Effects of monoclonal antagonist antibodies on calcitonin gene-related peptide receptor function and trafficking. J Headache Pain 2019;20:44.

10. Yarwood RE, Imlach WL, Lieu T, et al. Endosomal signaling of the receptor for calcitonin gene-related peptide mediates pain transmission. Proc Natl Acad Sci USA 2017;114:12309-12314.

11. Ramón C, Cernuda-Morollón E, Pascual J. Calcitonin gene-related peptide in peripheral blood as a biomarker for migraine. Curr Opin Neurol 2017;30:281-286. 


\section{Neurology}

\section{Potential for treatment benefit of small molecule CGRP receptor antagonist plus monoclonal antibody in migraine therapy}

Kathleen Mullin, David Kudrow, Robert Croop, et al.

Neurology 2020;94;e2121-e2125 Published Online before print January 13, 2020

DOI 10.1212/WNL.0000000000008944

This information is current as of January 13, 2020

Updated Information \&

Services

References

Citations

Subspecialty Collections

Errata

Permissions \& Licensing

Reprints including high resolution figures, can be found at: http://n.neurology.org/content/94/20/e2121.full

This article cites 10 articles, 2 of which you can access for free at: http://n.neurology.org/content/94/20/e2121.full\#ref-list-1

This article has been cited by 1 HighWire-hosted articles: http://n.neurology.org/content/94/20/e2121.full\#\#otherarticles

This article, along with others on similar topics, appears in the following collection(s):

All Headache

http://n.neurology.org/cgi/collection/all_headache Migraine

http://n.neurology.org/cgi/collection/migraine

An erratum has been published regarding this article. Please see next page or:

/content/94/20/900.1.full.pdf

Information about reproducing this article in parts (figures,tables) or in its entirety can be found online at:

http://www.neurology.org/about/about_the_journal\#permissions

Information about ordering reprints can be found online:

http://n.neurology.org/subscribers/advertise

Neurology ${ }^{\circledR}$ is the official journal of the American Academy of Neurology. Published continuously since 1951, it is now a weekly with 48 issues per year. Copyright Copyright ( 2020 The Author(s). Published by Wolters Kluwer Health, Inc. on behalf of the American Academy of Neurology.. All rights reserved. Print ISSN: 0028-3878. Online ISSN: 1526-632X.

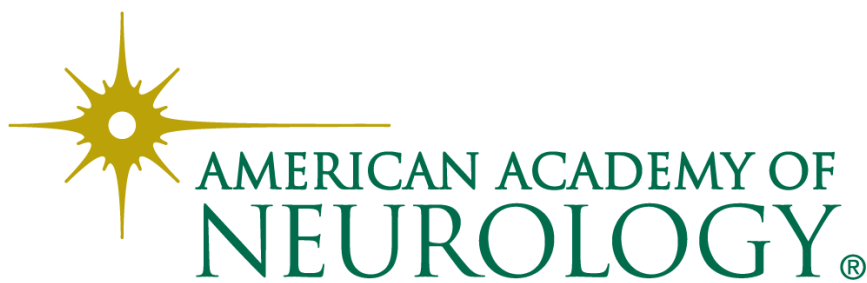




\section{Potential for treatment benefit of small molecule CGRP receptor antagonist plus monoclonal antibody in migraine therapy}

Neurology ${ }^{\circledR}$ 2020;94:900. doi:10.1212/WNL.0000000000009280

In the article "Potential for treatment benefit of small molecule CGRP receptor antagonist plus monoclonal antibody in migraine therapy" by Mullin et al., ${ }^{1}$ first published online January 13, 2020, the last sentence of the abstract's Results should read "While using rimegepant alone or together with erenumab, patients reported no related adverse events." The sentence appears correctly in the May 19, 2020, issue. The authors regret the error.

\section{Reference}

1. Mullin K, Kudrow D, Croop R, et al. Potential for treatment benefit of small molecule CGRP receptor antagonist plus monoclonal antibody in migraine therapy. Neurology 2020;94:e2121-e2125.

\section{Retinal defect in children with infantile spasms of varying etiologies An observational study}

Neurology ${ }^{\circledR}$ 2020;94:900. doi:10.1212/WNL.0000000000009279

In the article "Retinal defect in children with infantile spasms of varying etiologies: An observational study" by McFarlane et al., ${ }^{1}$ the percentage of vigabatrin-naive children (59 out of 312) should be $18.9 \%$ in the Abstract Results, in the Results section under the heading, "Prevalence of retinal defect in vigabatrin-naive children," and in table 3. Further, the second and third sentences in the Discussion should read, "We found that nearly a fifth of vigabatrin-naive children (before treatment with vigabatrin or $<4$ weeks of vigabatrin treatment) with IS showed evidence of a retinal defect on the $30-\mathrm{Hz}$ flicker ERG. Nearly a quarter of vigabatrin-naive children with a structural-acquired perinatal cause of spasms had an abnormal ERG." Finally, the first sentence of the last paragraph of the Discussion section should read, "The 30-Hz flicker ERG response is reduced in almost $19 \%$ of children under 3 years of age with IS who are naive to vigabatrin." The initial online version of the article has been republished with the corrected text along with a supplement (links.lww.com/WNL/B51) highlighting the errors, and the final version appears without the errors. The authors regret the errors.

\section{Reference}

1. McFarlane MT, Wright T, McCoy B, Snead OC III, Westall CA. Retinal defect in children with infantile spasms of varying etiologies: an observational study. Neurology 2020;94:e575-e582. 